\title{
InSAR、波形资料和GPS联合反演2015年皮山地震 震源破裂过程
}

\author{
王洵 ${ }^{1,2}$ ，王卫民 ${ }^{1^{*}}$, 赵俊猛 ${ }^{1}$, 姚振兴 $^{3}$ \\ 1. 大陆碰撞与高原隆升重点实验室, 中国科学院青藏高原研究所, 北京 100101; \\ 2. 中国科学院大学地球科学与行星学院, 北京 100049 ; \\ 3. 中国科学院地质与地球物理研究所, 北京 100029 \\ * 通讯作者, E-mail: wangwm@itpcas.ac.cn
}

收稿日期：2017-11-23; 收修改稿日期：2018-04-11; 接受日期：2018-05-30; 网络版发表日期：2018-07-23

国家自然科学基金项目(批准号: 41474036和41174037)、中国科学院“十三五”信息化建设专项项目(编号: XXH13505-06)资助

\begin{abstract}
摘要 2015 年7月3日新疆皮山县发生了 $M_{\mathrm{w}} 6.4$ 级地震, 震中位于塔里木盆地西南部的西昆仑山造山带北缘, 发震 断层为隐优断层. 文章基于分层地壳模型, 参考反射地震剖面构建铲状断层模型, 通过合成孔径干涉测量( InSAR) 数据、远场波形资料、全球定位系统(GPS)数据联合反演获得了此次地震的震源破裂过程. 表明该地震断层南

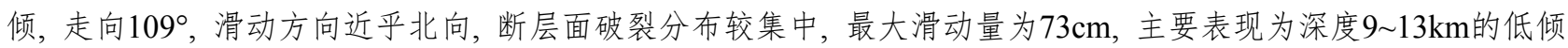
角( $\left.25^{\circ} \sim 10^{\circ}\right)$ 逆冲滑动, 传播时间约 $12 \mathrm{~s}$, 破裂由初始破裂点往周围扩散, 没有明显的方向性, 地表 $0 \sim 4 \mathrm{~km}$ 范围软硬沉 积层内没有明显滑动. 利用 InSAR时序分析方法获取了震源区震后两年内的形变速率, 雷达视线向(LOS)最大值 约 $17 \mathrm{~mm} \mathrm{a}^{-1}$, 仅在地震上盘观测到明显震后形变, 形变趋势与同震位移场类似，表明皮山地震没有完全释放区域 累积能量, 隐优断层上方的多层褶皱构造震后依然缓慢隆起, 其震后调整模式和余震危险性分析需要利用更多独 立数据进一步研究.
\end{abstract}

关键词皮山地震, 震源过程, 联合反演, 震后形变

\section{1 引言}

北京时间2015年7月3日9时7分，在中国新疆皮山 县发生了一次 $M_{\mathrm{w}} 6.4$ 级地震, 震中位置 $37.6^{\circ} \mathrm{N} 、 78.2^{\circ} \mathrm{E}$, 这次地震发生在青藏高原西北部、塔里木盆地西南部 的西昆仑造山带北缘(图1), 极震区烈度达到8度, 由于 当地建筑多为砖木结构, 房屋倒塌严重, 导致 3 人死亡, 约214人受伤(http://xj.people.com.cn/n/2015/0706/ c362096-25482237.html). 印度板块持续北向挤压导致 青藏高原与塔里木盆地互相推挤(Sobel和Dumitru, 1997), 西昆仑与塔里木块体的相对汇聚速率约为 $5 \mathrm{~mm} \mathrm{a}^{-1}$ (李海兵等, 2006), 山前发育有大量活动断裂 如西昆仑前陆逆冲断裂等和褶皱变形(肖安成等, 2000; Wang等, 2003). 地震震中处于以滑脱推覆为主 的皮山和田冲断构造带, 该构造带主要构造线近东西 向分布, 属于塔西南山前逆冲推覆构造(潘裕生, 1990; 


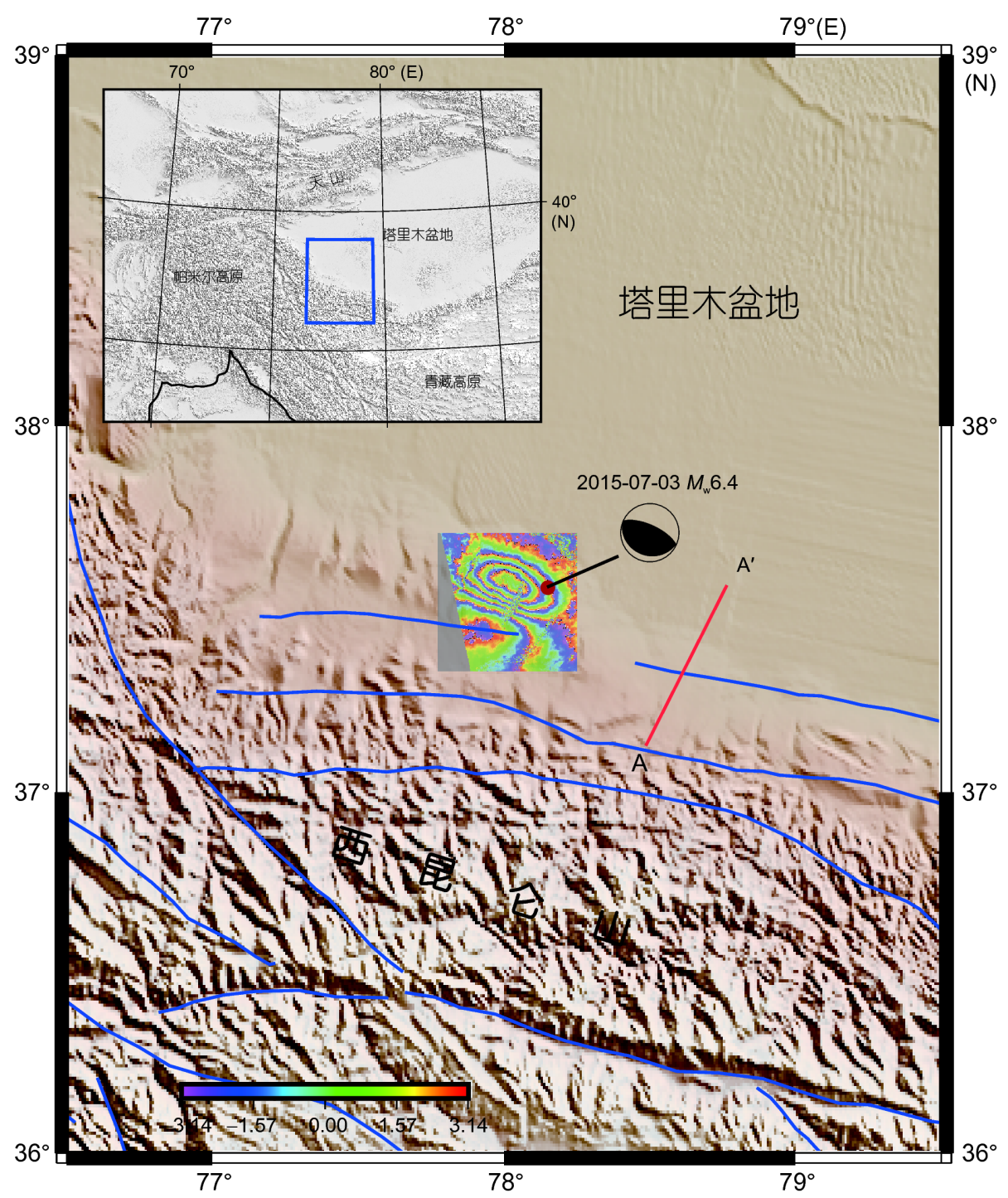

图 1 皮山地震构造背景及InSAR图像

黑色沙滩球为皮山 $M_{\mathrm{w}} 6.4$ 地震震源机制解, $\mathrm{AA}^{\prime}$ 为反射地震剖面(Jiang等, 2013)

Li等，2016)，位于其东部的阿尔金走滑断裂带平均滑 动速率约 $9 \mathrm{~mm} \mathrm{a}^{-1}$, 地震活动频繁 $(\mathrm{He}$ 等, 2013; Allen等, 2017), 相较而言近年来塔西南山前地震活动性较低, 人工地震反射剖面显示盆山过渡区域浅层地壳结构比 较复杂(高锐等, 2000; 李秋生等, 2000; Jiang等, 2013). 地震震源区处于塔里木戈壁沙漠和地形起伏强烈的西 昆仑山造山带之间，地理环境恶劣，缺乏近场台站资 料，震后野外调查发现在禇皱带的背斜顶部发育有一 系列正断层, 极震区内没有观测到明显地表破裂(吴传 勇等, 2017).

地震之后，多位学者对地震的成因和破裂滑动分
布进行了分析，得到的基本共同点是，此次地震是发 生在西昆仑山前隐伏断层的逆冲破裂事件，而由于采 用的资料、研究方法和地壳模型不同，在断层面倾角 和滑动分布细节等方面存在一定程度的差异, 或缺乏 震源破裂的时间信息(Feng等, 2016; Lu等, 2016; Sun 等, 2016; Wen等, 2016; Zhang等, 2016; He等, 2016b), 为获得详细、准确的震源破裂细节, 探讨西昆仑山前 逆冲断裂扩展方式以及青藏高原和塔里木块体的运动 和形变模式，本文使用这次地震的InSAR同震形变资 料，结合远场地震波形和GPS同震观测资料基于分层 地壳模型对地震震源过程开展研究, 并采用InSAR时 
序分析方法(Chaussard等, 2014; Tong和Schmidt, 2016) 对震源区震后形变进行分析.

\section{2 数据与方法}

本文基于分层地壳模型，采用有限断层方法反演 研究地震的破裂过程(Hartzell和Heaton, 1983; 姚振兴 和纪晨, 1997; 王卫民等, 2008), 引入不同观测资料约 束震源过程模型，联合反演获取更准确的震源破裂的 空间和时间信息. 从美国地震学研究联合会数据中心 获取皮山地震的远场台站(震中距 $30^{\circ} \sim 90^{\circ}$ ) 波形资料, 按照台站方位角均匀分布，挑选高信噪比的 27 个P波, 23 个SH波数据; 从欧空局获得Sentinel-1A覆盖震源区 的 23 幅雷达影像, 其中应用于同震研究的影像为 056 号 震前、震后 2 幅升轨雷达影像(表 1$),$ GPS资料为 6 个 GPS同震位移数据(He等, 2016b).

\subsection{D-InSAR形变场}

星载InSAR可以全天候，24h不间断对地观测，获 取空间连续覆盖的地表形变资料，广泛应用于地震、 火山等导致的地表形变测量的研究(Massonnet等, 1993; 单新建等, 2002). Sentinel-1A雷达由欧空局2014 年4月3日发射升空，2015年开始提供中国大部分地区 的雷达影像. Sentinel-1A正常回访周期为 24 天或 12 天, 与后续服役的Sentinel-1B卫星更能达到 6 天甚至更短 的回访周期，有助于及时获得地震产生的地表形变测 量数据，并降低时间去相干性概率. Elliott等(2015)首 次利用该雷达资料对 2014 年北加州纳帕 $M_{\mathrm{w}} 6.0$ 级地震 进行同震形变监测. 本文使用GMTsar程序(Sandwell 等，2011，2013)对干涉影像对进行差分处理，利用精 密轨道数据进行轨道校正，使用精度为 3 弧秒的 SRTM3 DEM去除地形效应，得到皮山地震的同震形 变场干涉图(图2)，相位解缠调用Snaphu模块(Chen和 Zebker，2002)，最后地理编码得到地面坐标的地表形 变场(图3).

皮山地震震源区北边是塔里木盆地戈壁沙漠，南 边是地形起伏强烈西昆仑山造山带. 如图2显示, InSAR影像干涉场上半区域即塔里木盆地去相干性较 强, 噪声严重, 相位解缠中采用的Snaphu方法在塔里木 盆地区域出现了解缠错误(图3). 但在地震震中区域即 西昆仑山前, 获得了完整清晰的InSAR干涉条纹图, 条
表 1 Sentinel-1A 影像参数 ${ }^{\mathrm{a})}$

\begin{tabular}{ccccc}
\hline 获取日期 & 轨道号 & 垂直基线 $(\mathrm{m})$ & 航向 & 倾角 \\
\hline $2015-06-30$ & 056 & $-56^{*}$ & $-13.2^{\circ}$ & $32.9^{\circ * *}$ \\
$2015-07-24$ & - & 0 & - & -
\end{tabular}

角

a) *, 同震形变干涉对相对基线长度; **, 震中附近雷达视线倾

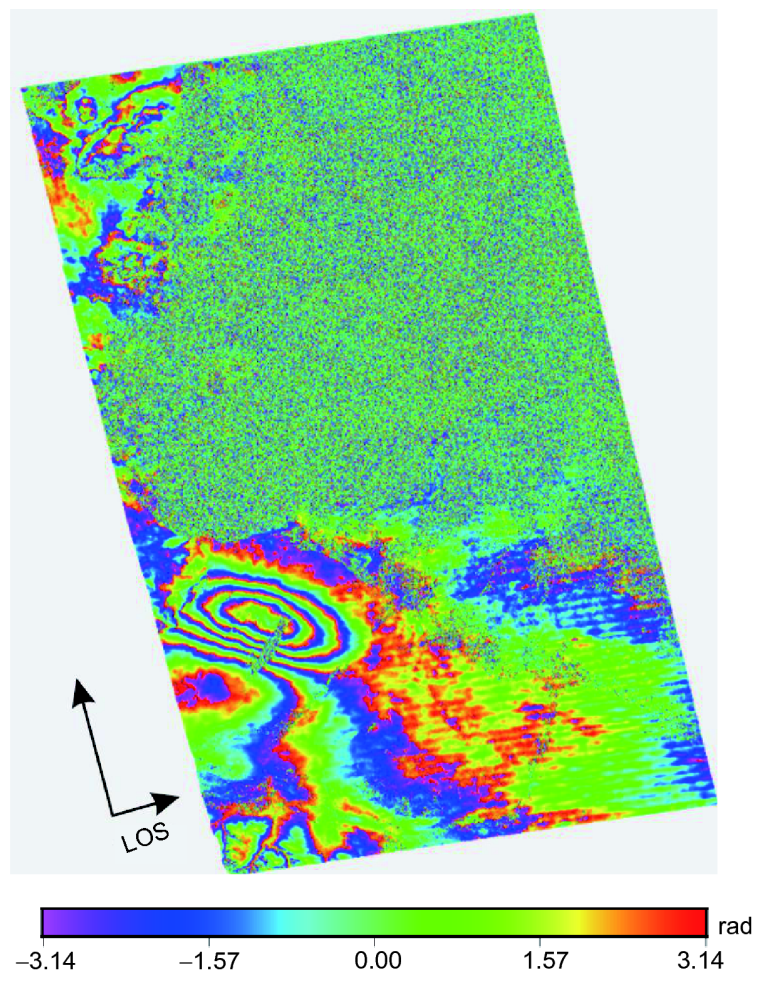

图 2 皮山地震InSAR干涉场

纹连续、平滑, 相位解缠得到的震中区域地表形变质 量较高. 因此, 需要剔除相干系数不高的区域, 反演时 仅采用震源区近场位移资料(图1中InSAR图像范围), 减少数据量的同时还保证了准确性. 震源机制解(表2) 表明, 皮山地震为逆冲型地震. 由干涉图可知, 地震上 盘雷达视线向抬升量将近 4 个条纹, 在上盘西南区域有 约 1 个条纹的雷达视线向沉降, 表示该区域有垂向向下 或东向位移量; 干涉图中没有观测到下盘形变量, 原因 可能是下盘地表为戈壁沙漠，该区域InSAR干涉图的 去相干性严重, 无法得到完整连续的干涉条纹.

\section{2 方法}

皮山地震发生在西昆仑山和塔里木盆地之间，由 


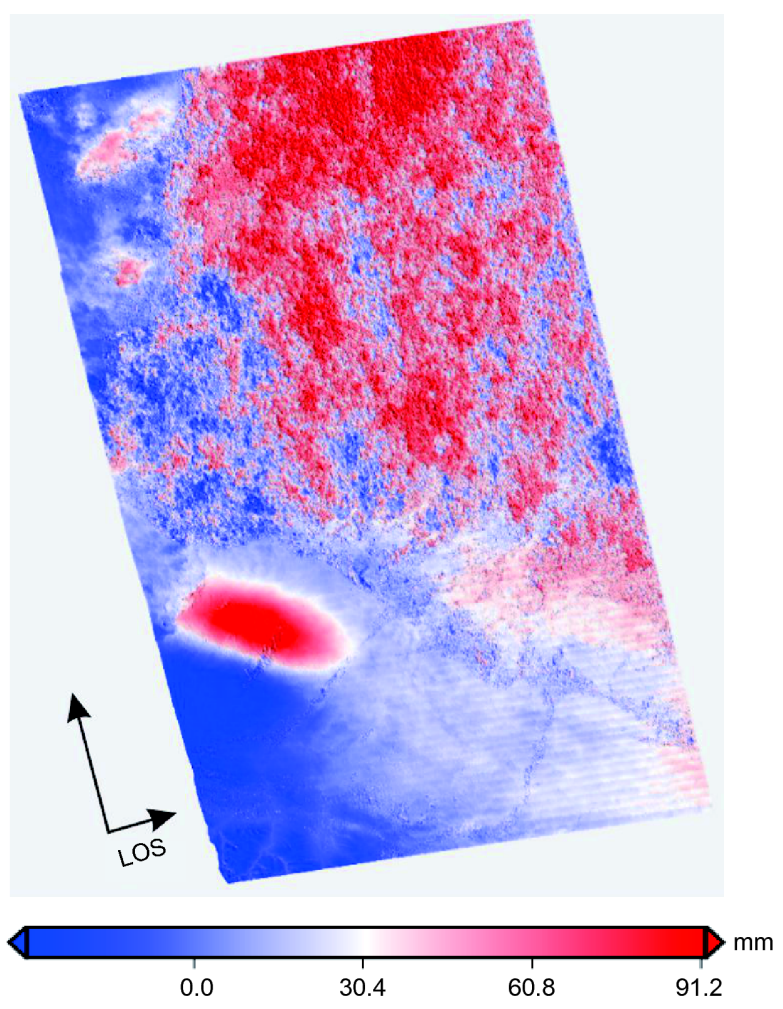

图 3 皮山地震同震形变场

于缺乏近场台站, 各个机构给的震中有差异, 定位震中 所处的板块不同将导致获得的地壳信息迥异. 本文结 合InSAR同震位移场，采用震中信息 $\left(37.53^{\circ} \mathrm{N}, 77.98^{\circ}\right.$ E), 由Crust2.0提取震源区地壳分层信息(Bassin等,
2000)如表3所示，震源区地壳厚度 $53 \mathrm{~km}$ ，其中软沉积 层厚度 $1 \mathrm{~km}$, 硬沉积层厚度 $2 \mathrm{~km}, \mathrm{P}$ 波平均速度为 $6.06 \mathrm{~km} \mathrm{~s}^{-1}, \mathrm{~S}$ 波平均速度为 $3.40 \mathrm{~km} \mathrm{~s}^{-1}$, 平均密度为 $2.80 \mathrm{~g} \mathrm{~cm}^{-3}$.

研究中采用分层介质模型(Crust2.0)计算静态位 移, 广义射线计算远场体波, 利用快速模拟退火技术实 现震源模型的非线性反演(王卫民等，2005，2015). 目 标函数的数学表达式为

$$
\begin{aligned}
\mathrm{e}= & {\left[\frac{1}{N_{W}} \sum_{j}^{N_{W}}\left(1-\frac{\int f_{j}(t) o_{j}(t) \mathrm{d} t}{\sqrt{\int f_{j}^{2}(t) \mathrm{d} t \cdot \int o_{j}^{2}(t) \mathrm{d} t}}\right)\right] \cdot w_{1} } \\
& +\left(\frac{1}{N_{g}} \sum_{k=1}^{N_{g}} \sum_{m=1}^{3}\left(O_{k, m}^{\mathrm{GPS}}-S_{k, m}^{\mathrm{GPS}}\right)^{2}\right) \cdot w_{2} \\
& +\left(\frac{1}{N} \sum_{i=1}^{N}\left(D_{i}^{\mathrm{O}}-D_{i}^{\mathrm{S}}\right)\right) \cdot w_{3}+\lambda \cdot K,
\end{aligned}
$$

式中，右边第一项为地震波形记录反演项， $N_{W}$ 为地震 台站数, $f_{j}(t)$ 为第 $j$ 个台站的理论地震图, $o_{j}(t)$ 为其观 测波形记录; 第二项为 GPS 同震位移数据反演项, $N_{g}$ 为GPS台站总数, $O_{k, m}^{\mathrm{GPS}}$ 和 $S_{k, m}^{\mathrm{GPS}}(m=1,2,3)$ 表示第 $k$ 个 GPS测点的三分量观测值和理论值; 第三部分为In$\mathrm{SAR}$ 同震位移场资料反演项, $D_{i}^{\mathrm{O}}$ 和 $D_{i}^{\mathrm{S}}$ 分别为第 $i$ 个 In-

\begin{tabular}{|c|c|c|c|c|c|c|}
\hline \multirow{2}{*}{ 来源 } & \multirow{2}{*}{ 震级 } & \multirow{2}{*}{ 震中 } & \multirow{2}{*}{ 深度 $(\mathrm{km})$} & \multicolumn{3}{|c|}{ 震源机制解 } \\
\hline & & & & 走向 & 倾角 & 滑动角 \\
\hline USGS & $M_{\mathrm{w}} 6.4$ & $37.459^{\circ} \mathrm{N}, 78.154^{\circ} \mathrm{E}$ & 15.5 & $317^{\circ} / 105^{\circ}$ & $69^{\circ} / 24^{\circ}$ & $102^{\circ} / 60^{\circ}$ \\
\hline 本文 & $M_{\mathrm{w}} 6.37$ & $37.53^{\circ} \mathrm{N}, 77.98^{\circ} \mathrm{E}$ & 12 & $109^{\circ}$ & $25^{\circ} \sim 10^{\circ}$ & $83^{\circ}$ \\
\hline
\end{tabular}
SAR数据采样点的雷达视线向(LOS)位移场观测值和

表 2 皮山地震震源机制解

表 3 皮山地震一维七层地壳模型

\begin{tabular}{ccccc}
\hline 地壳模型 & 厚度 $(\mathrm{km})$ & $V_{\mathrm{p}}\left(\mathrm{km} \mathrm{s}^{-1}\right)$ & $V_{\mathrm{s}}\left(\mathrm{km} \mathrm{s}^{-1}\right)$ & - \\
\hline 冰层 & 0 & - & - & - \\
水层 & 0 & - & 1.2 & 2.1 \\
软沉积层 & 1 & 2.5 & $\left.(\mathrm{~g} \mathrm{~cm})^{-3}\right)$ \\
硬沉积层 & 2 & 4.0 & 2.1 & 2.4 \\
上地壳 & 20 & 6.1 & 3.5 & 2.75 \\
中地壳 & 20 & 6.3 & 3.6 & 2.80 \\
下地壳 & 10 & 7.2 & 4.0 & 3.1 \\
\hline
\end{tabular}


合成理论值; 第四项约束条件为光滑因子, 用来控制相 邻子面元上滑动位移的物理连续性; $w_{1} 、 w_{2} 、 w_{3}$ 分别 为反演中地震波形记录、GPS数据、InSAR资料所占 的权重比, 在反演过程中, 按照经验给定各类资料所占 的权重比, 譬如数据完整性好, 精度高, 对反演模型约 束强的资料, 可以增加在反演中相对应的权重比, 最后 试算选定最优权重比组合.

\section{3 反演结果}

\section{1 平面断层模型InSAR反演}

对于中强震，在没有详细可靠的野外地质调查资 料和地质构造特征的情况下，可以采用固定倾角的断 层面来构建断层模型(Sun等, 2011; 张勇等, 2013). 皮 山 $M_{\mathrm{w}} 6.4$ 地震震中位于盆山过渡区域, 构造走向清晰, 因此可以尝试构建简单平面模型模拟发震断层. 首先, 单独采用InSAR形变位移场资料进行断层滑动分布反 演, 参考 $\mathrm{InSAR}$ 形变场特征, 构建 $38 \mathrm{~km} \times 26 \mathrm{~km}$ 的平面矩 形模拟地震断层面，沿走向和倾向划分为 $19 \times 13$ 个子 断层元，为提高反演效率，首先结合震源机制解和InSAR形变场确定断层南倾, 走向为 $109^{\circ}$, 倾角试算范围 为 $\left(24^{\circ} \sim 30^{\circ}\right)$. 基于上述分层地壳模型, 采用模拟退火算 法反演断层滑动分布，结果显示倾角 $27^{\circ}$ 时 InSAR资料 拟合较好. 平面断层模型及断层面滑动分布如图4所
示，显示较大滑动范围约 $8 \mathrm{~km} \times 6 \mathrm{~km} ，$ 集中在断层面沿 倾向 $12 \mathrm{~km}$ 处, 最大滑动量约 $75 \mathrm{~cm}$, 主要表现为逆冲滑 动, 破裂滑动没有扩展至地表, 沿断层面 $0 \sim 4 \mathrm{~km}$ 深度的 范围内几乎没有破裂滑动. 图5给出了地表形变观测值 与反演得到地表形变理论值的残差, 地表形变位移较 大的区域即地震上盘观测值和理论值拟合较好，在沉 降区域和相干性差的区域相对残差较大，原因可能是 构建的断层模型没有真实反映地壳结构, 而且与InSAR资料在相干性差的区域解缠得到的位移场误差较 大有关.

\section{2 铲状断层模型联合反演结果}

前人研究表明, 西昆仑山前缘发育有大量的推覆 构造，在盆山过渡带完成了大量的人工源地震探测， 对该区域的地壳精细结构进行了研究(高锐等, 2000; 李秋生等, 2000; Jiang等, 2013). 图6给出了距离震源 区最近的反射地震剖面(图1中的 $\mathrm{AA}^{\prime}$ 指示剖面位置), 揭示了该区域地壳构造形态(Jiang等, 2013), 结合震源 机制解，构建了一个倾角沿倾向变化的铲型断层模型 模拟发震断层(图7). 断层长和宽分别为 $51 \mathrm{~km} 、 39 \mathrm{~km}$, 划分为 $17 \times 13$ 个子断层元, 走向为 $109^{\circ}$, 倾角变化如图 6中黄线所示. 利用InSAR资料、GPS和远场波形资料 联合反演震源过程, 由图2和3可知, 震源区的InSAR干 涉图质量较高, 覆盖完全, 相干系数高, 反演中可相应

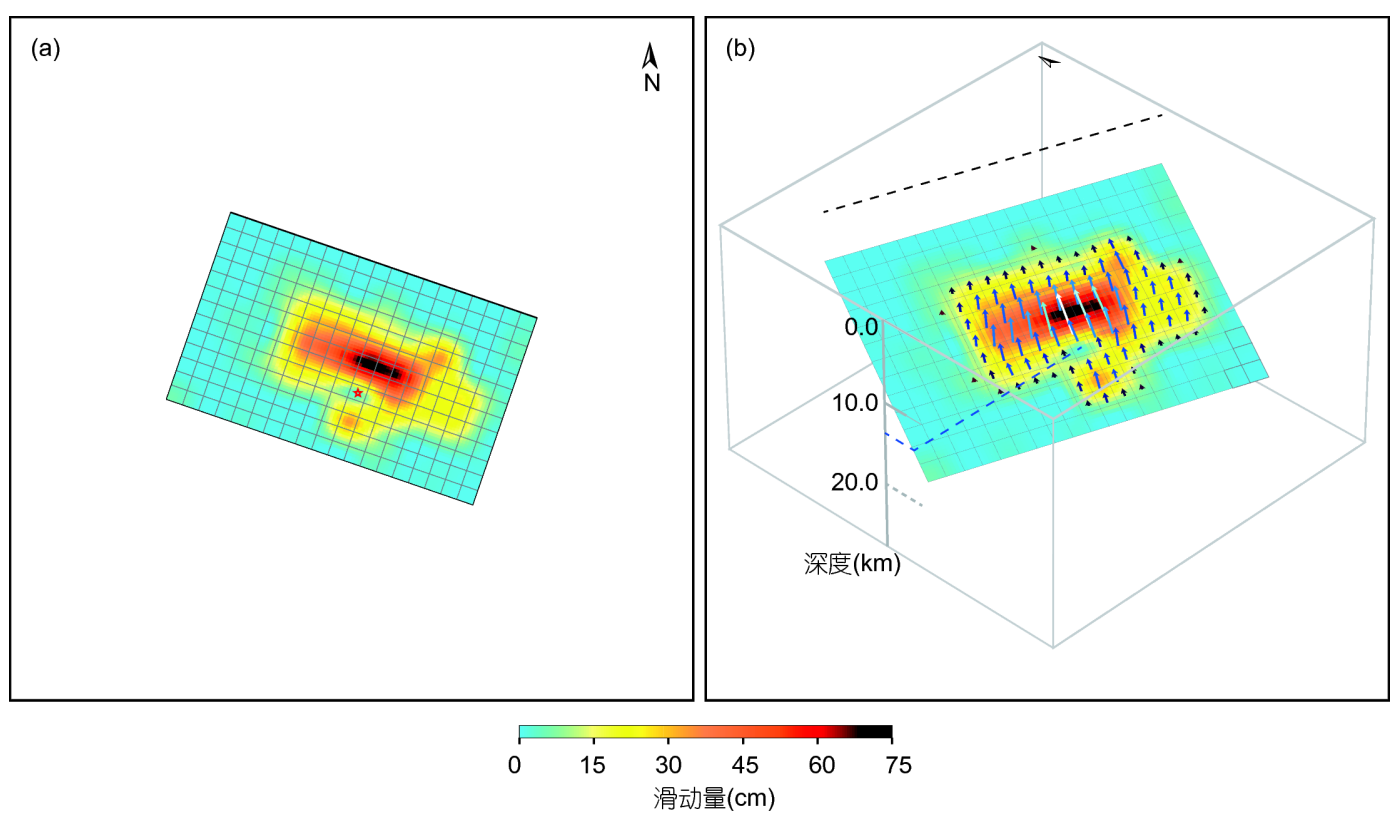

图 4 平面断层模型滑动分布投影(a)和三维示意图(b) 

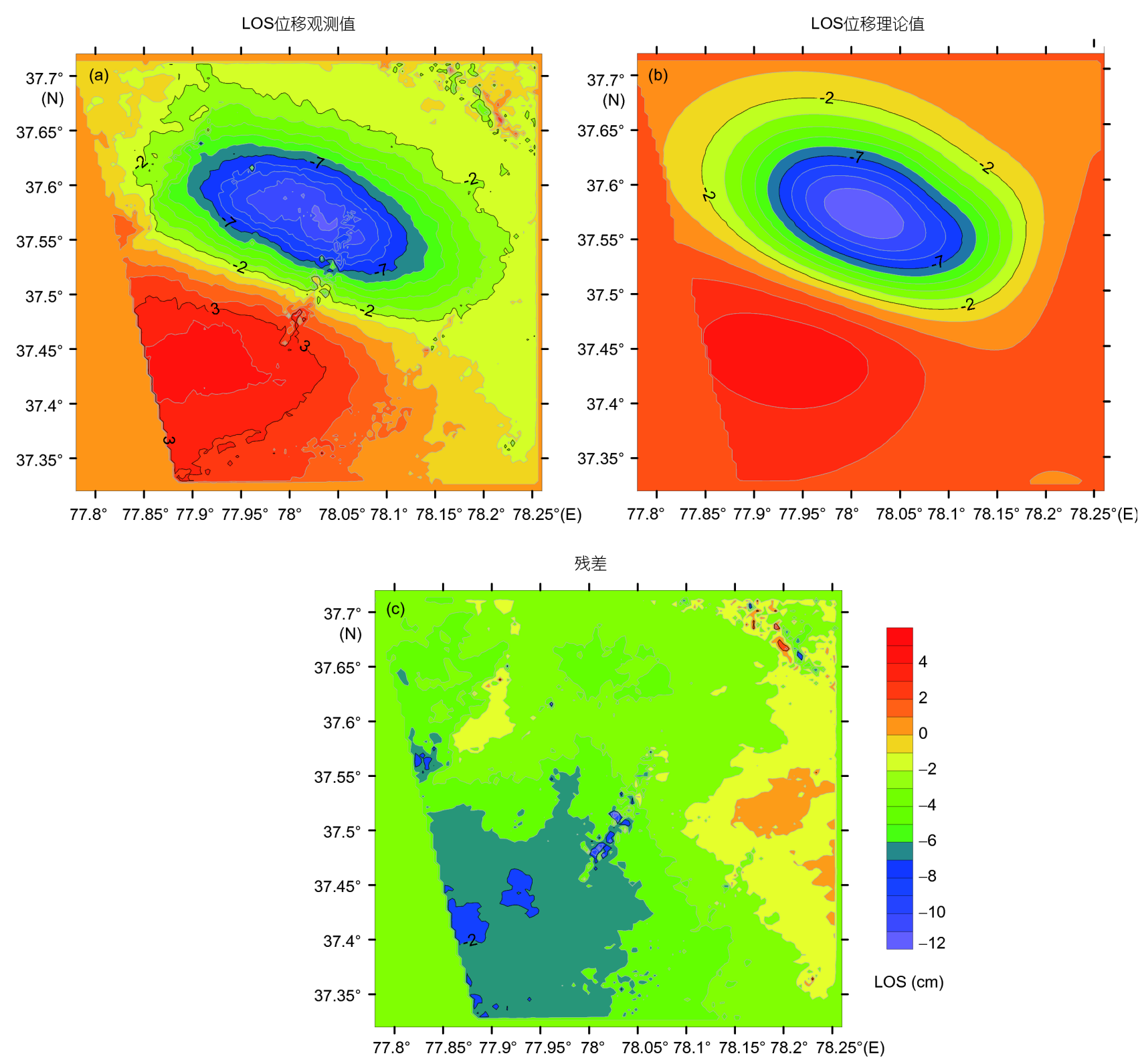

图 5 平面断层模型InSAR观测值与理论值的残差

(a) 平面断层模型皮山地震同震位移InSAR观测值; (b) 理论值; (c) 理论值与观测值残差

加大权重; 而 6 个GPS数据点相对较少，分布比较稀疏 且多数不在较大地表形变区域内，因此反演中GPS资 料所占的权重比考虑适当降低, 而GPS数据精度高, 准 确度好, 可以把它作为最终滑动分布模型产生地表理 论位移场的验证; 远场波形资料对断层面的破裂滑动 分布约束较低, 反演时参数的变化对其影响较大, 但 可以很好地约束震源的时间过程，而且最大振幅能更 好地约束断层面最大滑动量. 基于上述考虑, 固定GPS
的权重为 0.1 (数据点少且个别点距离震中较远), 波形 资料的与InSAR 资料的权重范围分别为 $(0.1 \sim 0.4)$ 、 $(0.8 \sim 0.5)$, 试算步长为 0.05 , 当InSAR同震形变场、GPS 同震位移值和地震远场波形资料这3 种数据在反演中 所占的权重比分别为 $0.7 、 0.1 、 0.2$, 光滑因子为 0.15 时, InSAR资料和波形记录的观测值和理论值拟合情 况均较好.

图7为联合反演获得的皮山地震的断层滑动分布. 


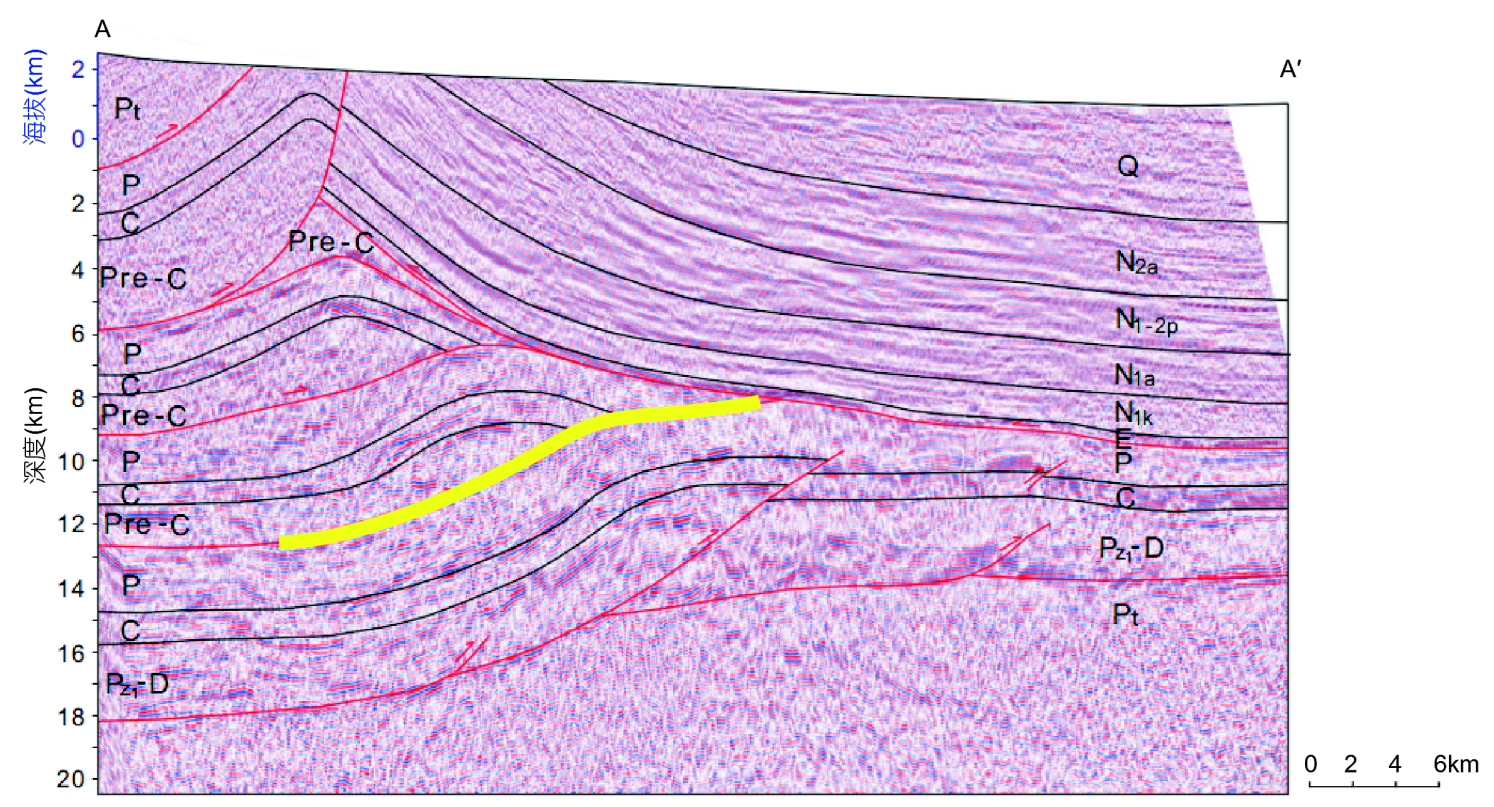

图 6 反射地震剖面及推测皮山地震发震构造(黄线)

据Jiang等(2013)
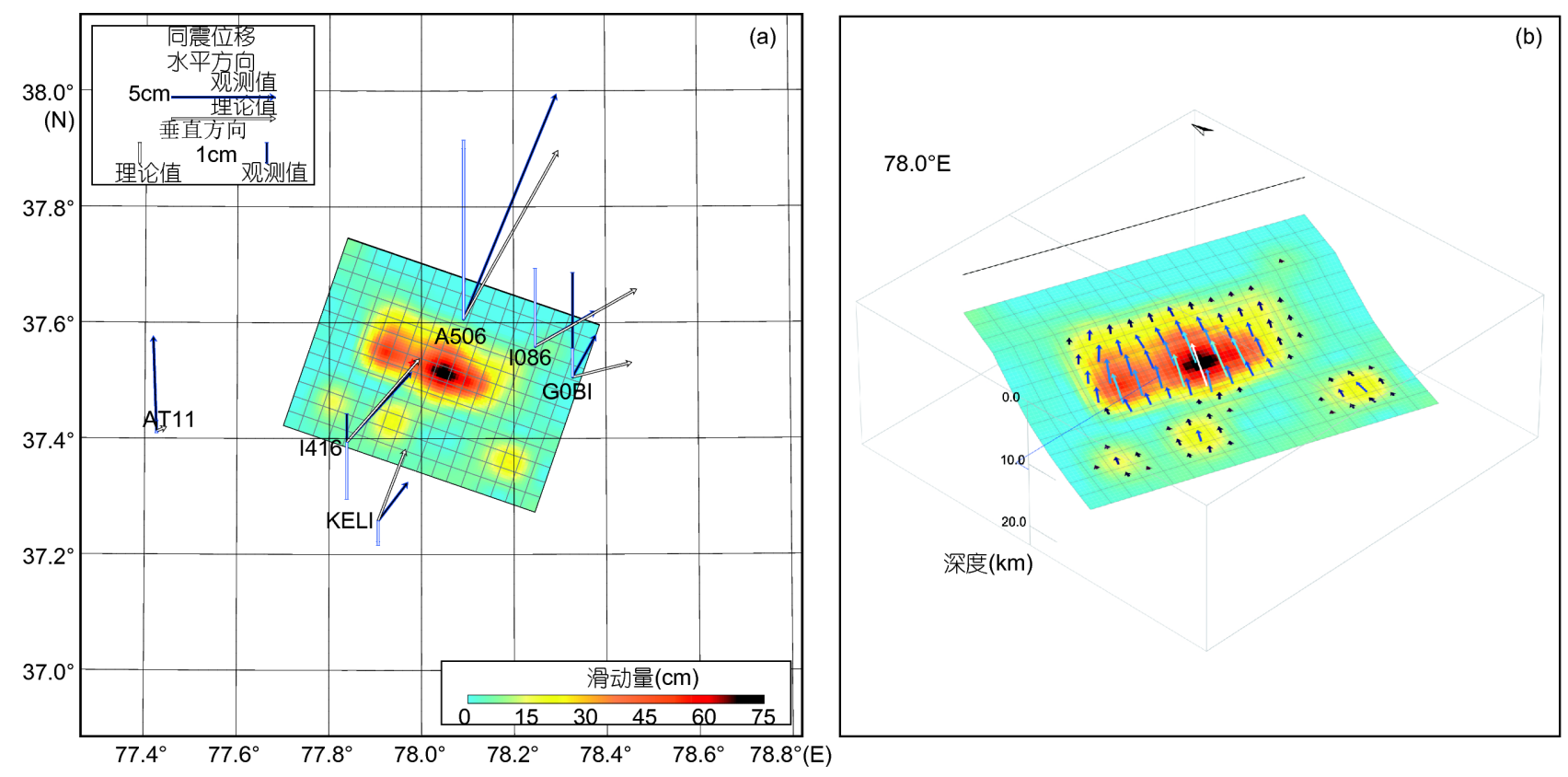

图 7 皮山地震断层滑动分布投影和三维示意图

(a) 断层滑动分布地表投影及GPS资料拟合情况, 箭头和短柱分别表示GPS同震位移的水平分量和垂直分量(深蓝色为观测值, 灰色为理论值); (b) 有限断层滑动分布三维示意图

图7a为破裂滑动在地表的投影和GPS资料的拟合情况， 震源区较大形变区域附近的 4 个 GPS测点的水平分量 位移值拟合情况较好, 最西的GPS测点(AT11)、最东
测点 $(\mathrm{G} 0 \mathrm{BI})$ 水平拟合偏差较大, 推测原因可能是InSAR测量水平方向精度比垂直方向低，另外GPS测点 位于戈壁沙漠地区，测量结果容易受区域地质条件的 
影响, 而且该区域InSAR资料噪声干扰较为严重, 解缠 之后获得的同震位移误差较大，从而导致拟合出现较 大偏差；图 $7 \mathrm{~b}$ 为滑动分布的三维示意图，显示破裂方 向基本上为北向逆冲，破裂没有到达地表处，断层面 破裂滑动分布集中，主要表现为深度9 13km的低倾角

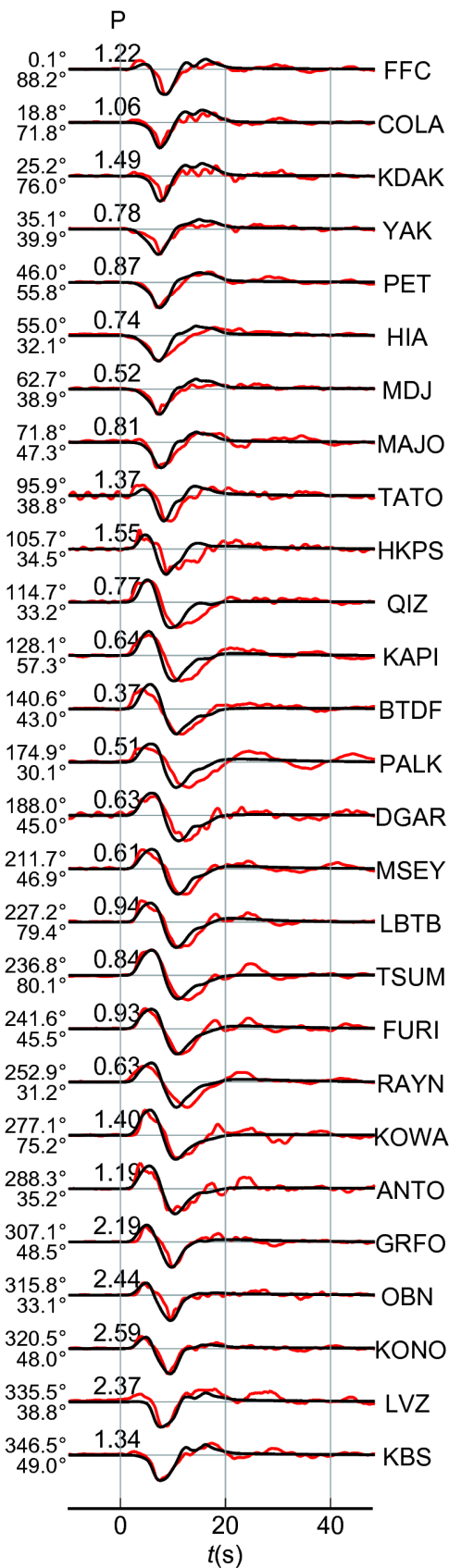

$\left(25^{\circ} \sim 10^{\circ}\right)$ 逆冲滑动, 最大滑动量 $73 \mathrm{~cm}$, 标量地震矩 $M_{0}=4.32 \times 10^{18} \mathrm{~N} \mathrm{~m}$, 换算为矩震级 $M_{\mathrm{w}} 6.37$.

图8为远场波形拟合结果，P波和S波波形相关性 均较好. 图9给出了InSAR观测值、合成LOS向理论值 和二者的残差结果，除了空间去相干性强的小部分区

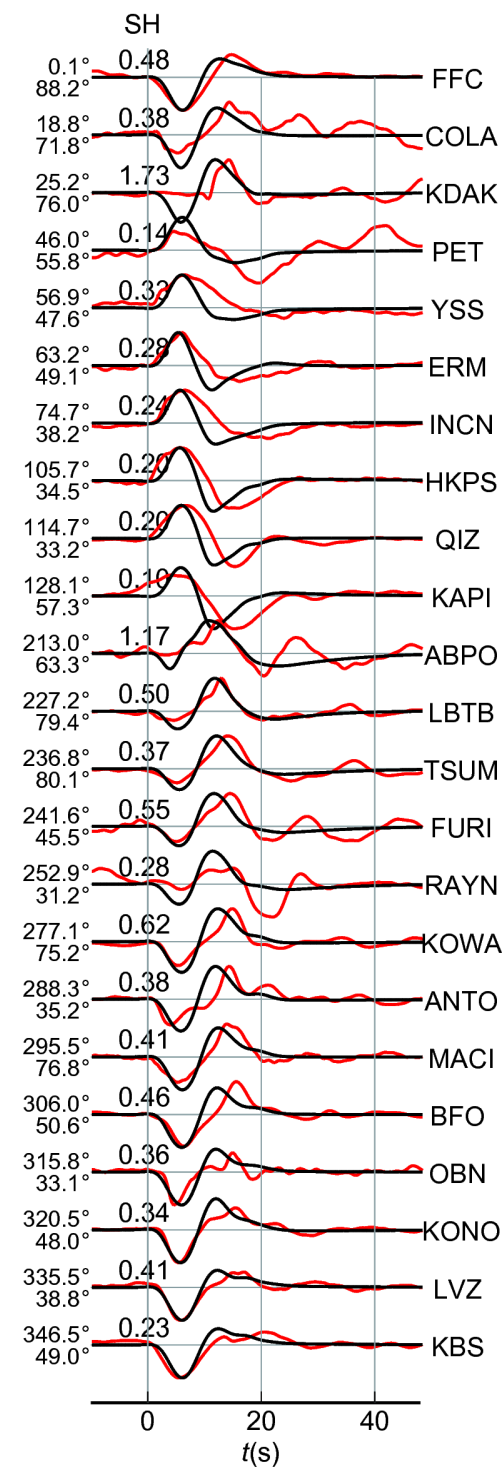

图 8 远场波形拟合

左列为 $\mathrm{P}$ 波垂向位移理论图(黑线)与记录(红线)的对比; 右列为 $\mathrm{SH}$ 波切向位移理论图(黑线)与记录(红线)的对比; 并给出每个记录的方位角(左 上)、震中距(左下)、振幅比(上)和台站名(右) 
域, 整体残差较小, 基本接近于零值, 而且没有出现区 域性残差异常, 表明这一形态的断层模型较平面断层
对InSAR资料的拟合更好. 图10给出了地震破裂的时 间过程，显示断层破裂没有明显的方向性，由震中往
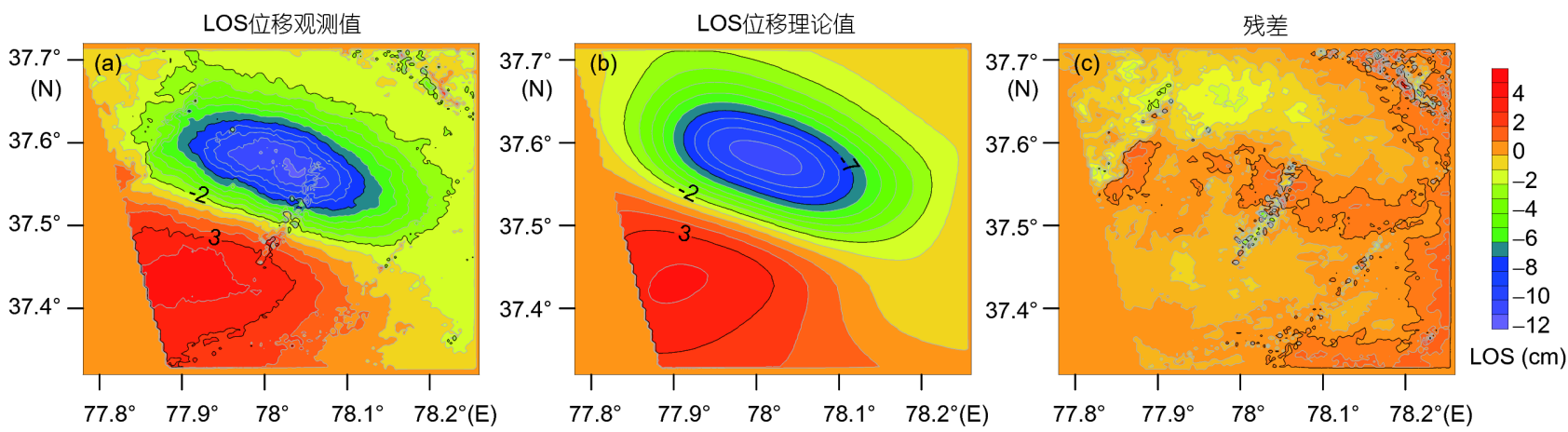

图 9 铲状断层模型LOS向同震位移拟合

(a) 铲状断层模型皮山地震同震位移InSAR观测值; (b) 理论值; (c) 理论值与观测值残差
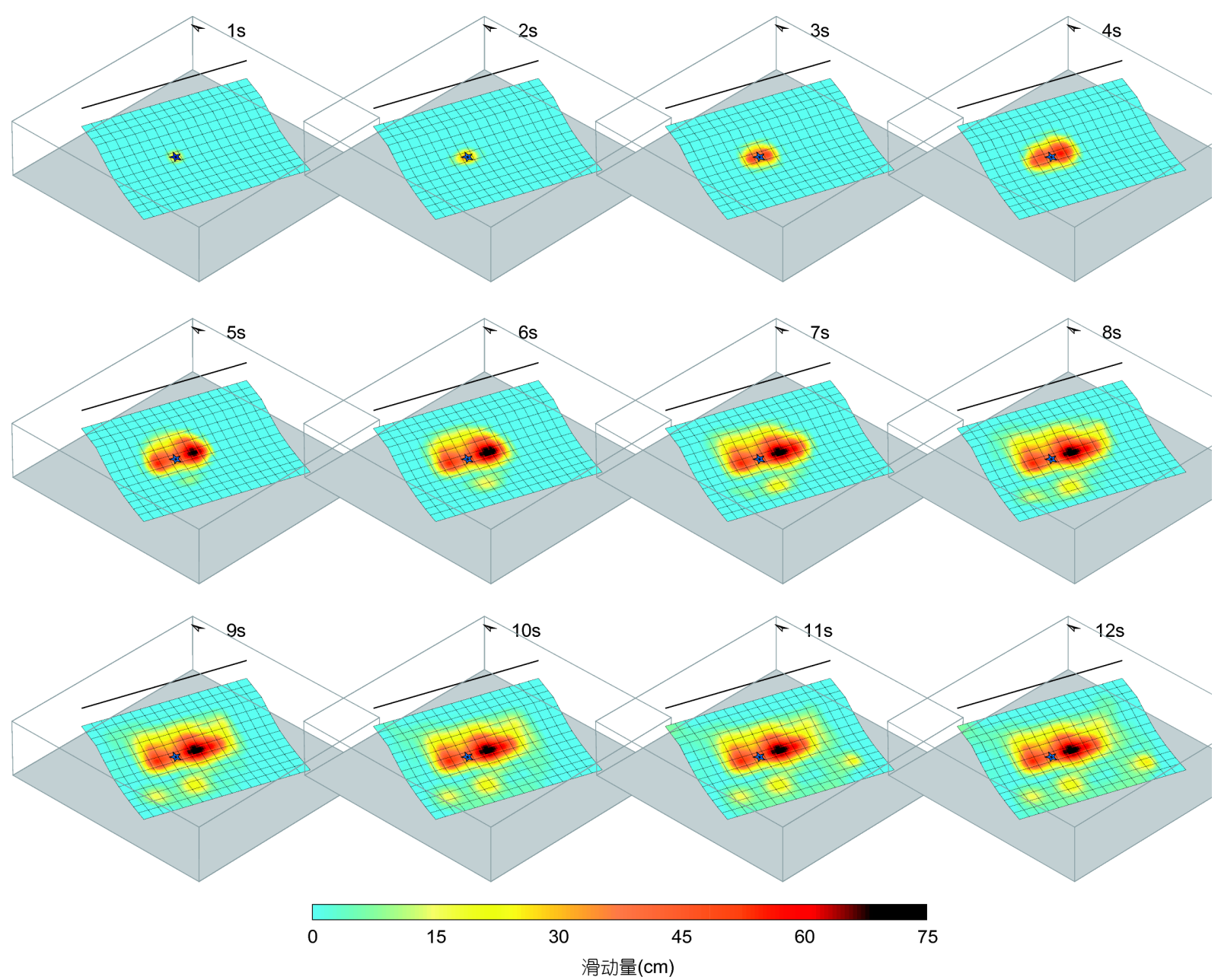

图 10 皮山地震破裂过程 
四周扩展, 破裂滑动持续约 $12 \mathrm{~s}$.

\section{4 讨论}

\section{1 模型分析}

皮山逆断裂-褶皱带的变形特征以地层的褶皱弯 曲为主，这一系列正断层是背斜顶部局部拉张应力形 成的弯矩断层，并形成了明显的陡坎地貌，表明该区 域历史上发生过多次褶皱型地震，造成褶皱隆升从而 背斜顶部形成弯矩断层; $M_{\mathrm{w}} 6.4$ 皮山地震也是一次典 型的褶皱型地震，破裂没有延伸至地表，而由于弯矩 作用在背斜顶端形成多条与背斜走向一致的地裂缝 (吴传勇等, 2017). 利用Sentinel-1A雷达影像资料得到 皮山地震震源区的地表位移干涉图, 条纹清晰, 连续, 解缠结果显示地表无明显破裂，与野外调查结果一致, 显示出新型雷达对地观测的优势, 而且覆盖区域广, 运 行周期更短, 可有效应用于地震的同震形变. 多样化的 幅宽模式有利于监测地表的长周期微量形变，如地震 震间形变或地表沉降等 $(X u$ 等, 2017; Shirzaei等, 2017). 结合前人获取的地壳结构形态(Jiang等，2013), 推断该地震断层属于塔里木西南缘的皮山盲逆断裂一 背斜带. 平面断层模型反演的拟合结果说明, 研究中强 震断层破裂滑动分布时, 在无先验信息的情况下, 如果 地表干涉场条纹集中、样式较为简单如同心椭圆等, 构建平面断层模型进行反演研究(Sun等, 2011; 张勇 等，2013), 可以获取接近真实的震源信息，解释地震 产生的同震位移、应变等; 综合铲状模型的结果, 断层 上盘南部的沉降区域残值比其他区域(除去空间去相 干性区域)大，推测该部分沉降可能不是完全由地震产 生的弹性形变, 可能是西昆仑山前隐伏断裂向前扩展, 断层上盘往塔里木盆地逆冲，断层面滑脱产生了一定 程度的地表下沉.

皮山地震宏观震中位于西昆仑山前缘、塔里木盆 地西南缘，属于高山与盆地的过渡区域, Crust2.0提取 地壳信息表明震源区存在厚度约 $1 \mathrm{~km}$ 的软沉积层和约 $2 \mathrm{~km}$ 厚的硬沉积层，沉积层的P波、 $\mathrm{S}$ 波速度与上地壳 差异很大(表2). 如果采用Okada弹性半空间模型, 将与 真实地壳情况相差甚远，因此有必要采用顾及沉积层 的分层地壳模型来进行正演计算, 降低地壳模型误差. 基于Crust2.0地壳模型和倾角沿倾向变化的铲状断层 模型，本文利用InSAR资料(Sentinel-1A)、GPS同震位
移数据、远场波形记录联合反演获得了皮山地震的破 裂过程. He等(2016b)利用ALOS-2雷达影像和GPS同 震位移数据，基于Okada模型构建平面断层反演得到 了此次地震的滑动分布; Sun等(2016)利用Sentinal-1A 影像获取了此次地震的断层滑动分布和三维地表形 变, 与本文结果对比发现, 反演得到的滑动分布具有一 定程度的相似性, 但本文结果中最大位移 $0.73 \mathrm{~m}$ 较 $0.63 \mathrm{~m}$ (He等, 2016b)、0.61 $\mathrm{m}$ (Sun等, 2016)大，且较大 滑动位置较深, 原因可能是本文采用的是Crust2.0分层 地壳模型, 正演计算中考虑了沉积层的影响, 另外构建 的断层模型的倾角逐渐平缓，如果计算格林函数时去 掉沉积层, 其他条件均不变, 断层滑动的最大值约 $0.67 \mathrm{~m}$, 略有减小; $\mathrm{He}$ 等(2016b)断层模型在地表 $0 \sim 4 \mathrm{~km}$ 区域发现有最大值约 $0.2 \mathrm{~m}$ 的较大范围的滑动，与较深 处 $(8 \sim 10 \mathrm{~km})$ 的较大滑动区域并不连续, He等(2016b)推 测原因可能是破裂跳过了“障碍体”继续往浅处传播, 也有可能是断层模型没有真实反映地下隐伏断层情 况, 或与采用Okada弹性地壳模型有关. 本文多种试算 模型包括去掉沉积层的影响，均没有在浅层得到明显 的滑动位移，与Sun等(2016)、Feng等(2016)反演结果 一致. 结合上述, 沉积层的影响不能忽视, 本文构建的 铲状断层模型能一定程度上反映真实断裂形态，各类 独立资料的观测值和理论值均拟合较好，采用多种资 料的联合反演获得的皮山地震破裂过程稳定、可靠.

\section{2 震后形变分析}

西昆仑山前逆冲断裂系地震活动性较低，与位于 其东部的大型走滑断裂-阿尔金断裂相比, 不仅地震活 动少, 震级也较低(Allen等, 2017). 图11为皮山地震滑 动分布地表投影和震后 5 个月内 4 级以上余震的分布情 况, 从余震的总体分布来看, 与断层的滑动分布范围负 相关性不是很强, 大部分还是发生在已经有滑动位移 的区域，这些余震既有局部库伦应力变化触发的，也 有是由于区域应力没有达到稳态产生的. 震后四个月 内GPS观测到震源区有显著区别于震间形变的位移值 (He等, 2016a), 为分析震源区的震后形变情况, 本文获 取了震后两年内 21 幅升轨雷达影像，轨道号为129号， 最早的影像获取时间为震后两天即 2015 年7月 5 日，最 晚影像为2017年6月24日获取.

利用InSAR资料处理获得了震后地表的形变干涉 图(图12), 时间间隔约为 5 个月、 11 个月、 2 年. 图中一 
$78^{\circ} \mathrm{E}$

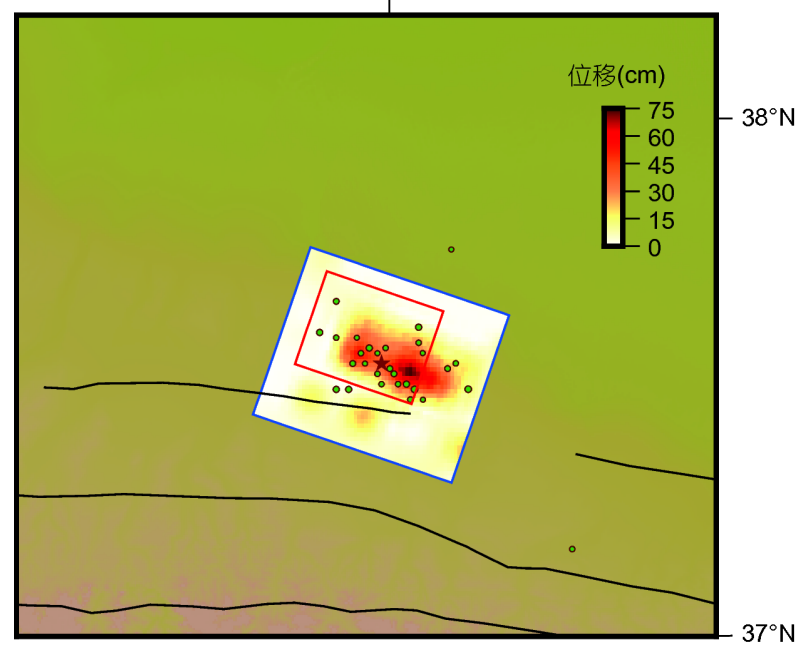

图 11 皮山地震滑动分布地表投影与余震(4级以上)

红色五角星为主震震中, 蓝色线框为主震断层地表投影, 红色线框 为震后模拟断层地表投影, 黑色实线表示活动断裂带
个完整干涉条纹表示位移为 $2.8 \mathrm{~cm}$, 基本上地表形变范 围与主震产生的较大地表形变区域有一定程度的一致 性, 随着时间的推移, 震源区的地表形变明显增大, 而 形变速率有降低的趋势, 两年后的形变位移达到约两 个干涉条纹; 由于震后形变尺度小，时间去相干性强， 干涉图受干扰严重信噪比低, 解缠得到的位移值误差 较大，尝试利用震后约 11 个月的影像进行震后断层滑 动反演研究. 由于震后形变是长时间、多种构造活动 如余震、褶皱隆升等形成的，需要模拟一个地震事件 来研究震后滑动分布, 模拟地震断层面地表投影如图 11 红色线框所示，位于主震断层面的西北部，断层模 型及滑动分布反演结果如图13所示，断层倾角约为 $13^{\circ}$, 虚拟震中较浅约 $6 \mathrm{~km}$, 属于一次逆冲事件, 最大滑 动量约 $15 \mathrm{~cm}$, 标量地震矩 $M_{0}=4.36 \times 10^{17} \mathrm{~N} \mathrm{~m}$, 相当于 $M_{\mathrm{w}} 5.7$ 级地震; 由于 $\mathrm{InSAR}$ 位移场信噪比低, 边缘误差 较大, 反演时形变量较大的中间区域拟合较好, 边缘区

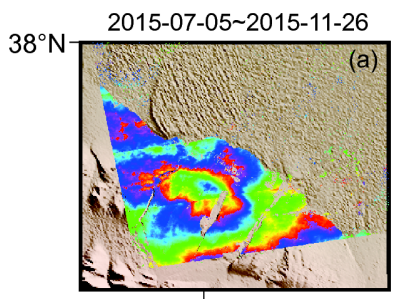

$78^{\circ} \mathrm{E}$

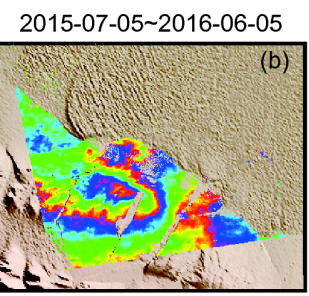

(b)

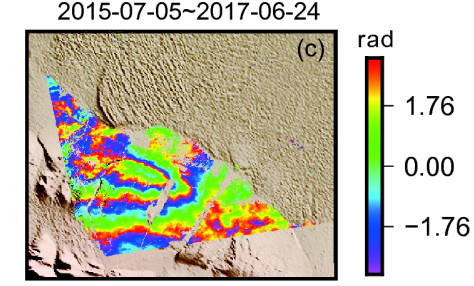

$-1.76$

图 12 皮山地震震后地表位移干涉图

时间间隔分别约为: (a) 5 个月; (b) 11 个月; (c) 两年

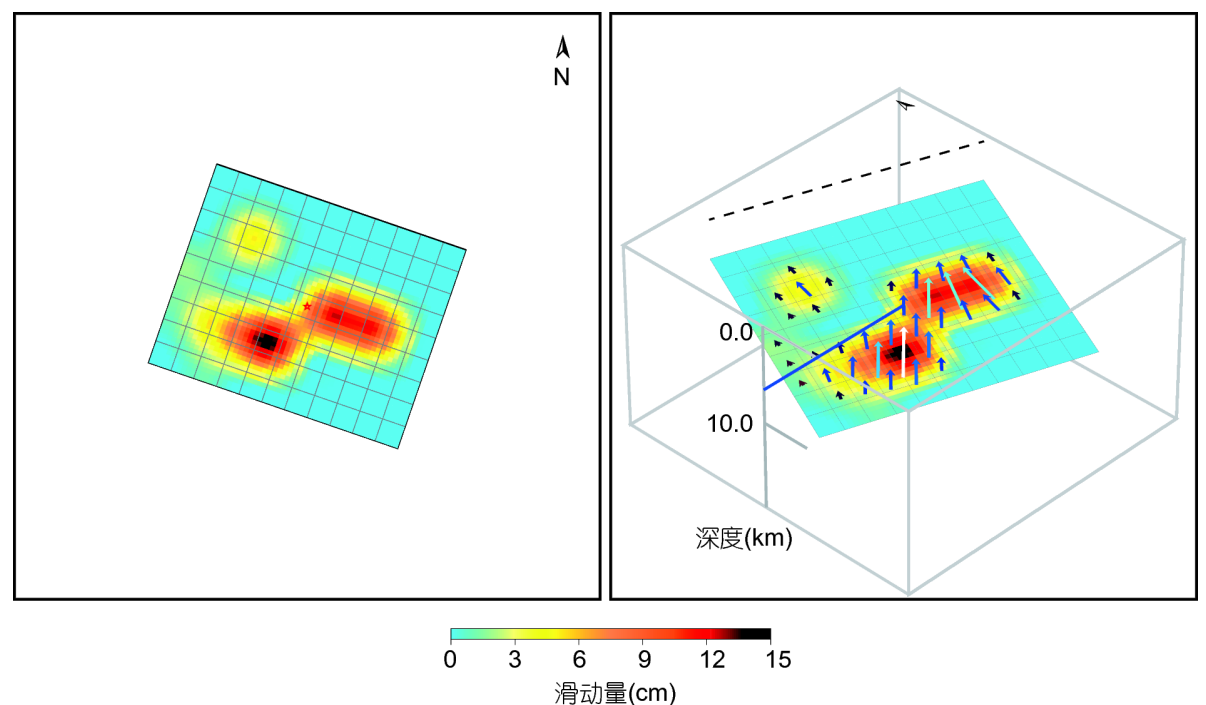

图 13 震后模拟断层模型及滑动分布 
域残差过大，原因可能是模拟断层模型不是最佳模型, 或者皮山地震震后形成的地表形变无法用一次简单的 地震事件来完全解释.

为获取震后形变速率，本文采用小基线集法 (SBAS)进行InSAR时序分析. 图14为以20150705号影 像为主影像时其他影像的相对基线信息和时间信息, 所有影像对的相对基线长度均在 $200 \mathrm{~m}$ 以内, 有利于降 低基线长度过长带来的干涉误差，考虑影像对的时间 相干性和相对基线长度，设定时间基线为 150 天，相对 基线长度为 $200 \mathrm{~m}$, 配对成 76 个影像对(图14), 处理得到 的形变速率如图15所示.

图15显示皮山地震震后震源区的地表LOS向形变 位移速率(近乎垂向)，西昆仑山前即地震上盘出现区 域性抬升现象，最大抬升速率约为 $17 \mathrm{~mm} \mathrm{a}^{-1}$ ，断层下
盘几乎没有变化，没有出现区域沉降的趋势，在沙漠 区域出现不规则的异常点，原因可能是沙漠的时变效 应制约了雷达影像对的干涉效果. 由图15右下图沿BB 剖面的形变速率趋势线可以看出, 形变速率呈不对称 性，山前南部较为平缓，北部相对梯度较大，这一特点 与皮山地震低倾角的发震断层十分吻合，同时表明震 后形变促进了隐伏断层上方褶皱的形成(Lu等，2016). 另外，断层上盘西南方的同震位移沉降区没有观测到 继续沉降的趋势, 基本处于稳定状态. 当然InSAR时序 分析对影像的质量要求较高, 可能会受当时大气水汽 等的干扰，当地季节性变化也会影响结果的可靠性， 如果震后在震源区布设高密度的高频连续GPS台站和 宽频带地震仪, 多种独立数据联合观测, 将有助于对震 后余震的监测和震后形变调节机制的研究，进行地震

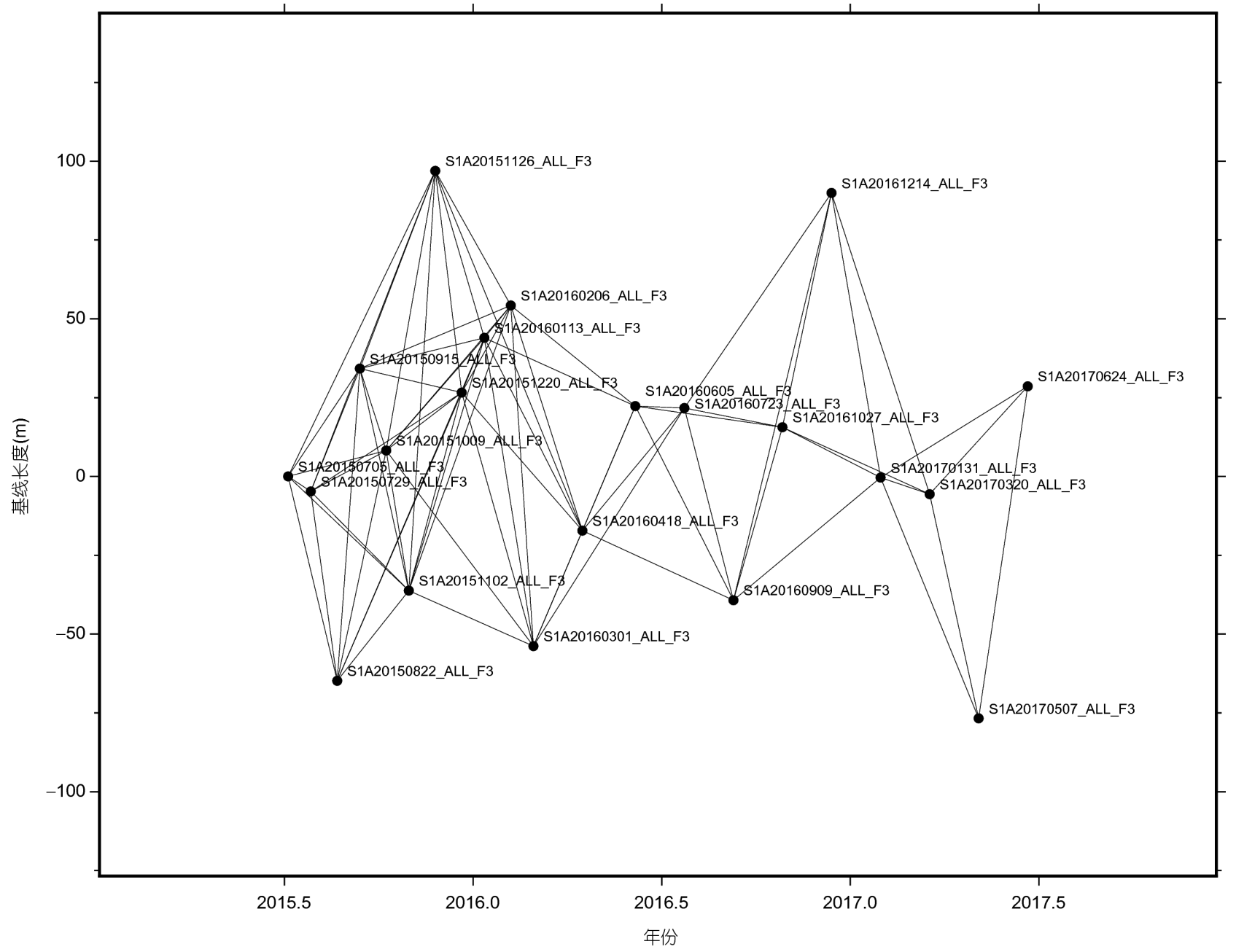

图 14 影像基线和时间信息 


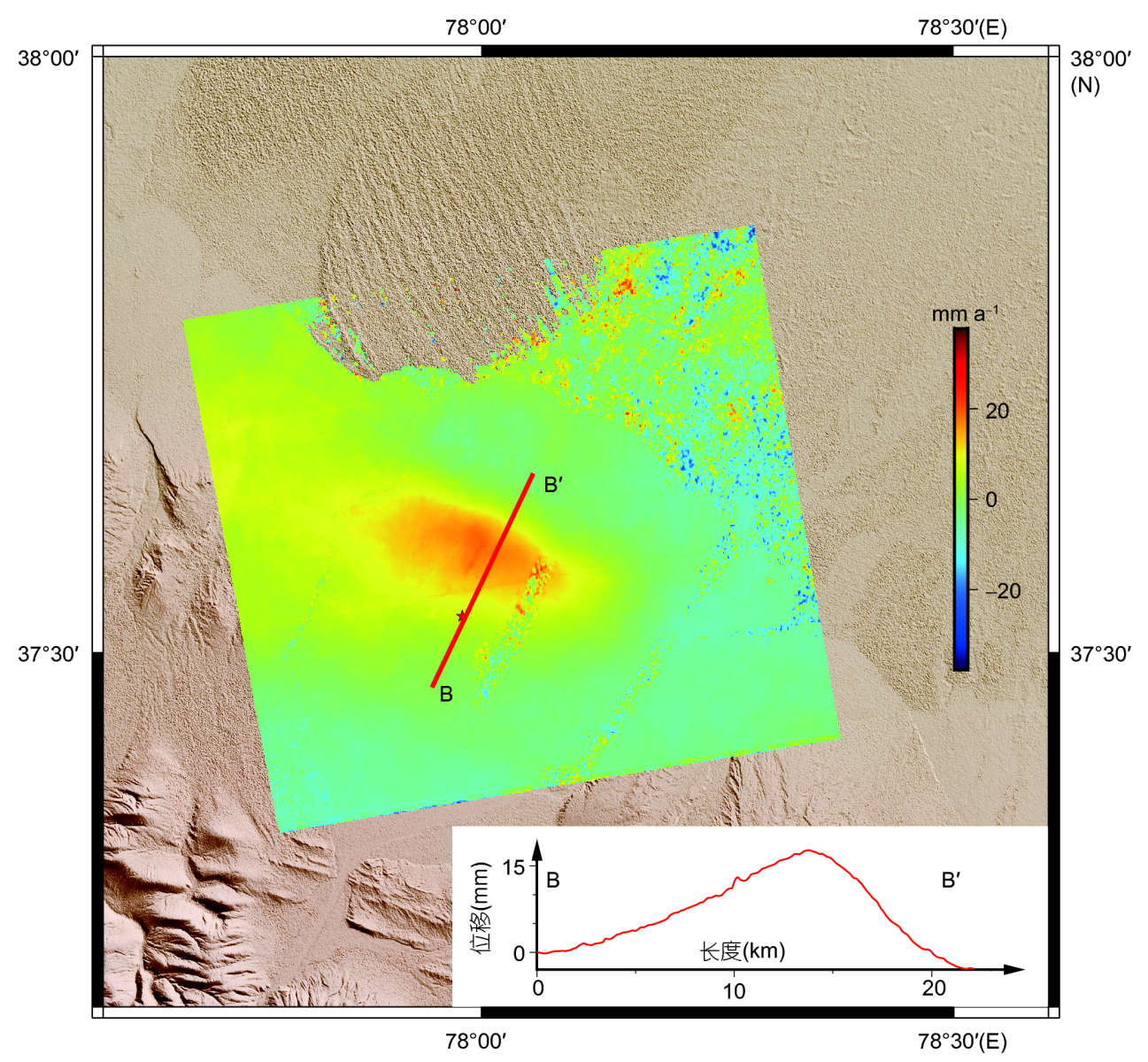

图 15 地理坐标下的震源区LOS向形变速率

红色五角星表示震中位置, 右下图为沿BB'剖面的形变速率

危险性评估, 为抗震救灾提供及时可靠的依据.

\section{5 结论}

基于Crust2.0地壳模型和倾角沿倾向变化的铲状 断层模型, 采用有限断层方法, 通过InSAR资料、远场 波形资料、GPS数据联合反演获得了 $M_{\mathrm{w}} 6.4$ 皮山地震 震源破裂过程, 表明该地震断层南倾, 位于皮山盲逆断 裂-背斜带, 走向 $109^{\circ}$, 滑动方向近乎北向, 倾角沿倾向 逐渐变低, 反演结果显示断层面破裂分布较集中, 较大 滑动量主要分布于长约 $15 \mathrm{~km}$ 、宽约 $9 \mathrm{~km}$ 范围内，最大 滑动量为 $73 \mathrm{~cm}$ ，破裂模式主要表现为深度 $9 \sim 13 \mathrm{~km}$ 的 低倾角 $\left(25^{\circ} \sim 10^{\circ}\right)$ 逆冲滑动, 震源破裂过程显示滑动传 播持续 $12 \mathrm{~s}$ ，由初始破裂点往周围扩散，没有明显的方 向性，地表 $0 \sim 4 \mathrm{~km}$ 范围即软硬沉积层内没有明显滑动.
推断断层上盘即西昆仑山北缘北向逆冲，与塔里木盆 地相互挤压, 致使上地壳缩短, 是该地震的主要成因. 由皮山地震震源模型可以推测西昆仑山前的北向逆冲 仍在进行，为研究青藏高原西北缘地壳缩短和上地壳 形变模式等提供初始数据和依据

InSAR干涉图显示震源区震后存在显著的形变调 整, 震后 11 个月内地表位移约等效于 $M_{\mathrm{w}} 5.7$ 级地震产生 的形变. 利用SBAS时序分析方法, 观测到震后两年内 断层上盘形变速率最大值约 $17 \mathrm{~mm} \mathrm{a}^{-1}$, 其形变趋势与 同震位移场有一定的相似性，表明皮山 $M_{\mathrm{w}} 6.4$ 主震没 有完全释放该区域所积累的能量，而且震后形变对褶 皱的隆升起到促进作用，其形变模式受隐伏断层上方 存在的多层禇皱带构造背景影响. 由于影像间隔时间 制约和精度的限制，要进一步探讨地震震后调节机 制、震后形变何时停止，评估余震的风险性，地震后 
在震源区进行高精度的连续对地观测和余震监测有一 定的必要性.

致谢远场波形资料由IRIS提供, Sentinel-1A 影像资料 由欧空局(ESA)提供，本文图件由 GMT软件生成，在此一 并致谢, 并感谢本文的审稿人及引用文献的研究者.

\section{参考文献}

高锐, 黄东定, 卢德源, 钱桂, 李英康, 匡朝阳, 李秋生, 李朋武, 冯如 进, 烨管. 2000. 横过西昆仑造山带与塔里木盆地结合带的深地 震反射剖面. 科学通报, 45: 1874-1879

李海兵, Valli F, 许志琴, 杨经绥, Tapponnier P, Lacassin R, 陈松永, 戚 学祥, Chevalier M L. 2006. 喀喇昆仑断裂的变形特征及构造演 化. 中国地质, 33: 239-255

李秋生, 卢德源, 高锐, 李敬卫, 范井义, 熊贤明, 张之英, 刘文, 李英 康, 问全人, 李德兴. 2000. 横跨西昆仑-塔里木接触带的爆炸地震 探测. 中国科学D辑: 地球科学, 30(S1): 16-21

潘裕生. 1990. 西昆仑山构造特征与演化. 地质科学, 17: 224-232

单新建, 马瑾, 王长林, 柳稼航, 宋晓宇, 张桂芳. 2002. 利用星载DINSAR技术获取的地表形变场提取玛尼地震震源断层参数. 中 国科学D辑: 地球科学, 32: 837-844

王卫民, 赵连锋, 李娟, 姚振兴. 2005. 1999年台湾集集地震震源破裂 过程. 地球物理学报, 48: 132-147

王卫民, 赵连锋, 李娟, 姚振兴. 2008. 四川汶川8.0级地震震源过程. 地球物理学报, 51: 1403-1410

王卫民, 郝金来, 何建坤, 姚振兴. 2015. 2015年4月25日尼泊尔 $M_{\mathrm{w}} 7.9$ 级地震震源过程. 中国科学: 地球科学, 45: 1421-1426

吴传勇, 李金, 刘建明, 胡伟华, 吴国栋, 常想德, 姚远, 向志勇. 2017 新疆皮山 $M_{\mathrm{S}} 6.5$ 地震——发生在西昆仑山前的一次褶皱地震. 地 震地质, 39: 342-355

肖安成, 杨树锋, 陈汉林, 贾承造, 魏国齐. 2000. 西昆仑山前冲断系 的结构特征. 地学前缘, (S2): 128-136

姚振兴, 纪晨. 1997. 时间域内有限地震断层的反演问题. 地球物理 学报, 40: 691-701

张勇, 许力生, 陈运泰. 2013. 芦山4.20地震破裂过程及其致灾特征初 步分析. 地球物理学报, 56: 1408-1411

Allen M B, Walters R J, Song S, Saville C, De Paola N, Ford J, Hu Z, Sun W. 2017. Partitioning of oblique convergence coupled to the fault locking behavior of fold-and-thrust belts: Evidence from the Qilian Shan, northeastern Tibetan Plateau. Tectonics, 36: 16791698

Bassin C G L, Laske G, Masters G G. 2000. The current limits of resolution for surface wave tomography in North America. Eos Trans AGU, 81: F897
Chaussard E, Wdowinski S, Cabral-Cano E, Amelung F. 2014. Land subsidence in central Mexico detected by ALOS InSAR time-series. Remote Sens Environ, 140: 94-106

Chen C W, Zebker H A. 2002. Phase unwrapping for large SAR interferograms: Statistical segmentation and generalized network models. IEEE Trans Geosci Remote Sens, 40: 1709-1719

Elliott J R, Elliott A J, Hooper A, Larsen Y, Marinkovic P, Wright T J. 2015. Earthquake monitoring gets boost from new satellite. Eos, 96 : $14-18$

Feng G, Li Z, Xu B, Shan X, Zhang L, Zhu J. 2016. Coseismic Deformation of the $2015 M_{\mathrm{w}} 6.4$ Pishan, China, earthquake estimated from Sentinel-1A and ALOS2 data. Seismol Res Lett, 87: 800-806

Hartzell S H, Heaton T H. 1983. Inversion of strong ground motion and teleseismic waveform data for the fault rupture history of the 1979 Imperial Valley, California, earthquake. Bull Seismol Soc Amer, 73: 1553-1583

He J, Vernant P, Chéry J, Wang W, Lu S, Ku W, Xia W, Bilham R. 2013. Nailing down the slip rate of the Altyn Tagh fault. Geophys Res Lett, 40: 5382-5386

He P, Wang Q, Ding K, Li J, Zou R. 2016a. Coseismic and postseismic slip ruptures for $2015 M_{\mathrm{w}} 6.4$ Pishan earthquake constrained by static GPS solutions. Geodesy Geodyn, 7: 323-328

He P, Wang Q, Ding K, Wang M, Qiao X, Li J, Wen Y, Xu C, Yang S, Zou R. 2016b. Source model of the $2015 M_{w} 6.4$ Pishan earthquake constrained by interferometric synthetic aperture radar and GPS: Insight into blind rupture in the western Kunlun Shan. Geophys Res Lett, 43: 1511-1519

Jiang X, Li Z X, Li H. 2013. Uplift of the West Kunlun Range, northern Tibetan Plateau, dominated by brittle thickening of the upper crust. Geology, 41: 439-442

Li T, Chen J, Fang L, Chen Z, Thompson J A, Jia C. 2016. The 2015 $M_{\mathrm{w}} 6.4$ Pishan Earthquake: Seismic hazards of an active blind wedge thrust system at the Western Kunlun Range Front, Northwest Tibetan Plateau. Seismol Res Lett, 87: 601-608

Lu R, Xu X, He D, Liu B, Tan X, Wang X. 2016. Coseismic and blind fault of the 2015 Pishan $M_{w} 6.5$ earthquake: Implications for the sedimentary-tectonic framework of the western Kunlun Mountains, northern Tibetan Plateau. Tectonics, 35: 956-964

Massonnet D, Rossi M, Carmona C, Adragna F, Peltzer G, Feigl K, Rabaute T. 1993. The displacement field of the Landers earthquake mapped by radar interferometry. Nature, 364: 138-142

Sandwell D, Mellors R, Tong X, Wei M, Wessel P. 2011. GMTSAR: An InSAR Processing System Based on Generic Mapping Tools. Office of Scientific \& Technical Information Technical Reports

Sandwell D, Mellors R, Tong X, Wei M, Wessel P. 2013. Open radar interferometry software for mapping surface Deformation. Eos 
Trans AGU, 92: 234

Shirzaei M, Bürgmann R, Fielding E J. 2017. Applicability of Sentinel1 terrain observation by progressive scans multitemporal interferometry for monitoring slow ground motions in the San Francisco Bay Area. Geophys Res Lett, 44: 2733-2742

Sobel E R, Dumitru T A. 1997. Thrusting and exhumation around the margins of the western Tarim basin during the India-Asia collision. J Geophys Res, 102: 5043-5063

Sun J, Johnson K M, Cao Z, Shen Z, Bürgmann R, Xu X. 2011. Mechanical constraints on inversion of coseismic geodetic data for fault slip and geometry: Example from InSAR observation of the 6 October $2008 M_{w} 6.3$ Dangxiong-Yangyi (Tibet) earthquake. J Geophys Res, 116: B01406

Sun J, Shen Z K, Li T, Chen J. 2016. Thrust faulting and 3D ground deformation of the 3 July $2015 M_{\mathrm{w}} 6.4$ Pishan, China earthquake from Sentinel-1A radar interferometry. Tectonophysics, 683: 77-85

Tong X, Schmidt D. 2016. Active movement of the Cascade landslide complex in Washington from a coherence-based InSAR time series method. Remote Sens Environ, 186: 405-415

Wang E, Wan J, Liu J. 2003. Late Cenozoic geological evolution of the foreland basin bordering the West Kunlun range in Pulu area: Constraints on timing of uplift of northern margin of the Tibetan Plateau. J Geophys Res, 108: 2401

Wen Y, Xu C, Liu Y, Jiang G. 2016. Deformation and Source Parameters of the $2015 M_{\mathrm{w}} 6.5$ Earthquake in Pishan, Western China, from Sentinel-1A and ALOS-2 data. Remote Sens, 8: 134

Xu X, Sandwell D T, Tymofyeyeva E, Gonzalez-Ortega A, Tong X. 2017. Tectonic and anthropogenic deformation at the Cerro Prieto geothermal step-over revealed by Sentinel-1A InSAR. IEEE Trans Geosci Remote Sens, 55: 5284-5292

Zhang G, Shan X, Zhang Y, Hetland E, Qu C, Feng G. 2016. Blind thrust rupture of the $2015 M_{\mathrm{w}} 6.4$ Pishan earthquake in the Northwest Tibetan Plateau by joint inversion of InSAR and seismic data. J Asian Earth Sci, 132: 118-128

(责任编委: 杨顶辉) 